\title{
A METHODOLOGY TO SIMULATE MEDIUM TERM MORPHOLOGICAL CHANGES IN A PRACTICAL COMPUTING TIME
}

\author{
Nestor Jimenez ${ }^{1}$ and Roberto Mayerle ${ }^{1}$
}

\begin{abstract}
In this paper the assessment of the preliminary results of a methodology to enable predictions of medium-term morphodynamics accounting for the effects of storms is carried out. The methodology integrates the approaches based on a morphological acceleration factor and on the empirical orthogonal functions to account respectively for the morphological changes on the medium and short term. In a very simplified fashion, the effects of the storms are represented by a superposition of most relevant bathymetrical changes. The effectiveness of the methodology was assessed for a coastal stretch along the German Baltic Sea. The analysis of the simulations of morphodynamics for a period of 10 years showed that the method is able to predict volumetric changes along the coastal stretches reasonably well. However it fails to describe the spatial variation of the morphological changes near the coast. Sensitivity studies show also that the results are significantly affected by the set-up scheme of the methodology. Preliminary results during the assessment of the methodology gave clues about the evolution of the morphology of the German Baltic Sea coast. The methodology can be used as a practical tool for initial assessments of tendencies of morphological evolution. Obviously, in this investigation, the method proposed to account for to the storms is a simplified representation of the reality. In this regard, further research is needed to include a more realistic representation of the chronology taking into account their intensity.
\end{abstract}

Keywords: medium-term morphodynamics; empirical orthogonal functions; morphological acceleration factor; German Baltic Sea

\section{INTRODUCTION}

Nowadays a consensus on the effects of storms on the medium and long term geomorphological evolution of the coastal zones has not yet been reached (Anderson et al., 2010). Some authors argue that the effects of extreme events are only temporary and that during fairly weather conditions the shore-face recovers completely (Zhang et al., 2002). Others found that the cumulative effects of the storms are permanent (Costas et al., 2005). To improve the understanding of the relevance of the storms in the morphological evolution of coastal areas extensive analyses of measured beach profiles and bathymetries, as well as, physical and numerical model studies, have been documented (Frazer et al., 2009; Houser et al., 2007). Nevertheless, in order to improve the understanding of the medium- and long-term coastal morphodynamics some serious limitations need to be overcome. For example, in the development and application of numerical morphodynamic models, the computational time is still restrictive for those simulations covering longer periods. For engineering projects and management protection plans relatively quick decisions have to be taken and hence numerical models have to be speeded up. At the present, there is no scheme in which speed-up methods are used to include the effects of extreme events. It is usually the case that through the use of those acceleration techniques the morphodynamics are simulated for representative periods of calm conditions in which storm events are not present. An additional limitation is found with respect to the process of calibration and validation of the morphodynamic models for the simulation of storms. It is a common practice to collect bathymetrical data during periods of calm conditions in which the measurement devices are more operable and easier to install. Therefore the actual effect of the storms on the morphodynamics is rarely known.

As a first attempt to overcome part of these limitations, a methodology is proposed in this paper. It integrates several statistical approaches to account for the medium term morphodynamics due to normal conditions and the short term effects of storms on the morphological developments. It should be born in mind that the inclusion of the storms is a simplified representation of the reality. The authors recommend more investigation, in which the chronology and intensity of the storms are taken into account. The effectiveness of the methodology for a coastal area on the German Baltic Sea is discussed based on the preliminary results presented in this paper.

\section{STUDY AREA}

The study area is the inner Luebeck Bay on the German Baltic Sea. The Luebeck Bay is located in the southernmost area of the Mecklenburg Bay (Figure 1). The Mecklenburg Bay is well recognized for its elongated shape southwards. In its widest section, in the north-eastern part of the bay, it reaches about $33 \mathrm{~km}$, while, in the south-east, across the inner Luebeck Bay, the area is about $12 \mathrm{~km}$ wide.

\footnotetext{
${ }^{1}$ Research and Technology Centre Westcoast, University of Kiel, Otto-Hahn-Platz 3, 24118 Kiel, Germany
} 
Figure 2 shows the most relevant geomorphological features of the study area and the three areas used in the analysis of the results. The Kuhlbrooktal ( 15m depth), constitutes the deepest region in the western Luebeck Bay. Near the Niendorf Harbour, a shallow area with depths less than 10m divides the bay in its western and eastern sub-domains. The Aalbeek channel, on the eastern side of the bay, is the deepest region of the Luebeck Bay with depths up to about $18 \mathrm{~m}$. Farther to the east, between the Aalbeek Channel and the mouth of the Trave River, a shallow area in front of the Brodten Cliff-coast is identified. Two distinct coastal types are observed along the inner Luebeck Bay: i) on the western side, the beach slopes are gentle and broad, ii) towards the east, in the foreshore of the Brodten, cliffs-coasts and narrow beaches are present.

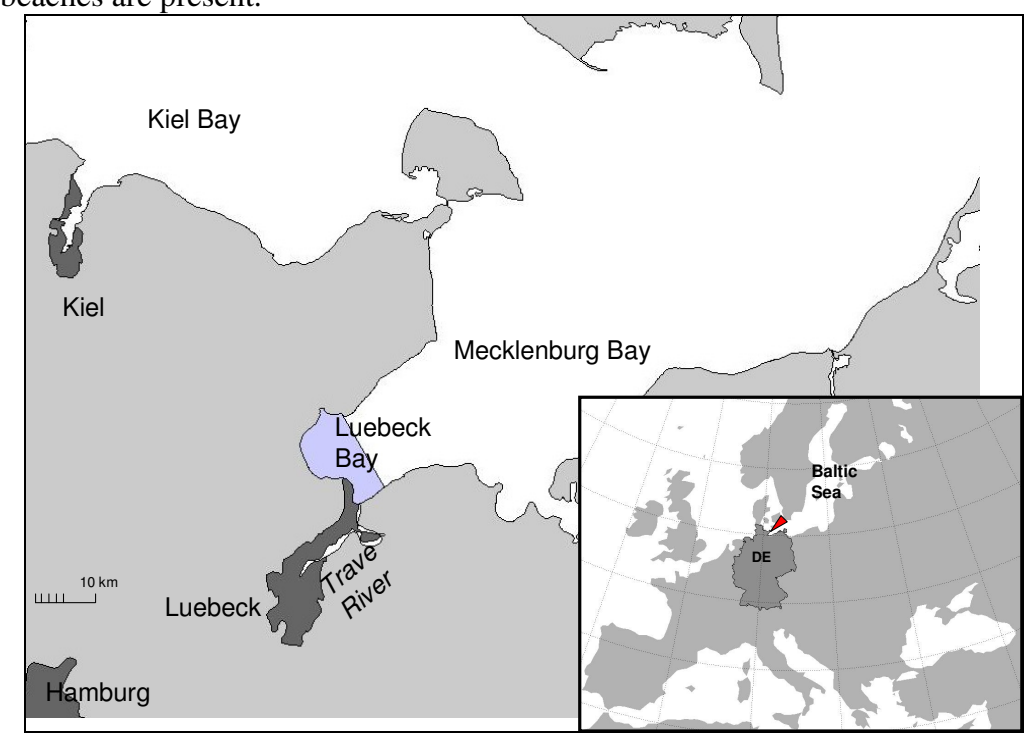

Figure 1. Location of the study area

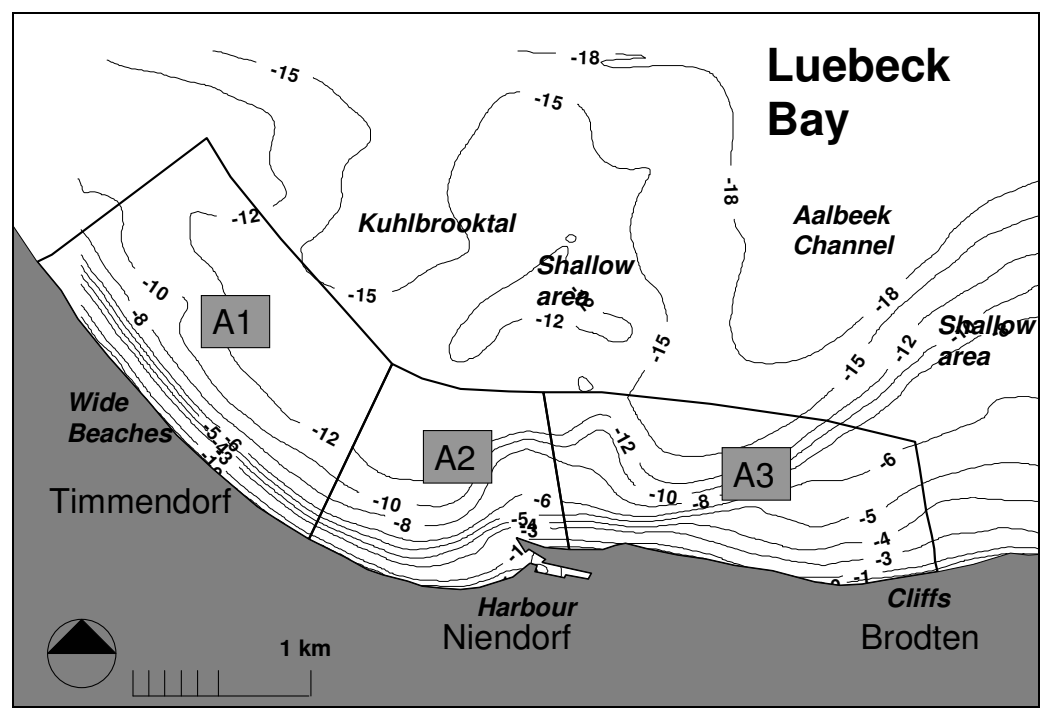

Figure 2. Geomorphology features and local areas along the shoreline

The earlier investigations on the sediment characteristics in the Luebeck Bay date back to the beginning of the second half of the last century (Kannenberg, 1952). Pratje (1948) presented an initial study on the distribution of the size of the sediment of the southern and central Baltic Sea. The results of those initial studies showed that in the deepest areas of the Luebeck Bay deposits of clay and mud are the main components of the sediment. It was also found that the deposits of fine- and median-sand are the main constituent of the sediment along the shoreline areas. More recently, a more detailed 
geological survey was carried out in the area (Schwarzer and Krause, 2008). According to those findings, sediment with grain size smaller than $0.06 \mathrm{~mm}$ is normally found in the deepest areas. In the shallower areas, in the center of the study area and offshore the Brodten Cliff-coast, conglomerates of residuals are commonly observed. The sediment on the beaches of the Luebeck Bay is principally characterized by medium-sand, which provides the ideal conditions for an active area of constant morphological changes.

The hydrodynamics in the Baltic Sea are principally dependent on the wind action and, the barotropic and baroclinic gradients due to the exchange of masses of the saline waters of the North Sea and the brackish waters of the Baltic Sea. Tides of small amplitudes not higher than $15 \mathrm{~cm}$ are commonly observed. One of the first studies on the hydrodynamics in the Luebeck Bay was done by Dietrich et al. (1952). The circulation patterns in the bay were investigated following the currents generated by north-easterly winds, before, during and after the occurrence of a storm. The presence of regular circulation patterns providing exchange of water masses between the inner Luebeck Bay and the Mecklenburg Bay was identified. Relevant patterns of convergence and divergence of currents were also determined along the coastline. Recent results of numerical model simulations of currents and waves (see Jimenez et al., 2009) revealed quite distinct features of currents and waves for both normal and storm conditions in the Luebeck Bay. Figure 3 shows the distinct patterns of currents and waves during a normal period without storms and in the presence of storms. There is a tendency of the storms to produce regions of recirculation with clockwise movement of water offshore of Timmendorf, Niendorf and Brodten. Besides, the wave heights are also quite distinct. Under storm conditions significant wave heights of more than $1.5 \mathrm{~m}$ in the deeper areas are considerably dissipated when approaching the shoreline. Under normal conditions significant wave heights are around $0.3 \mathrm{~m}$.

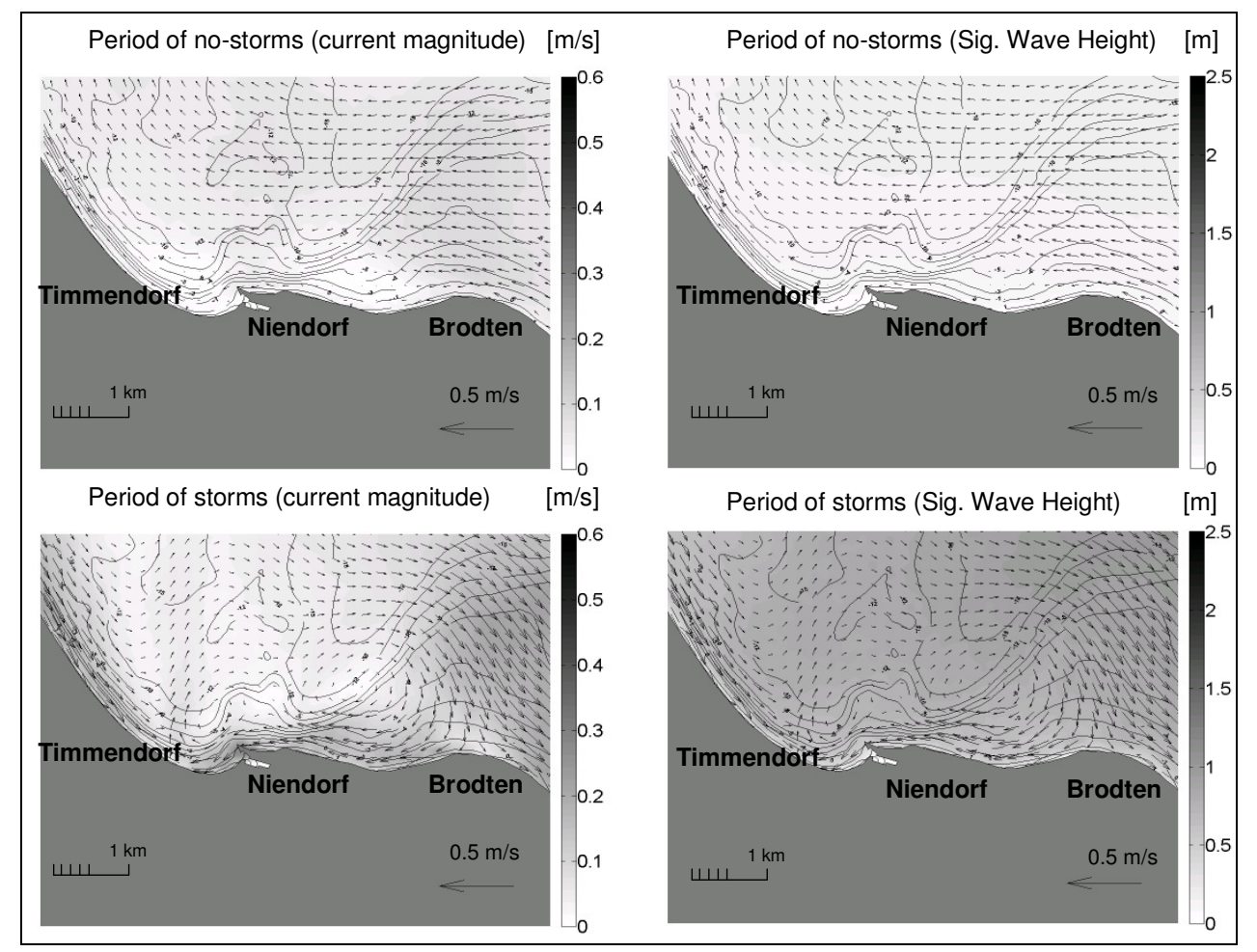

Figure 3. Current and wave patterns under normal (upper panels) and storm (lower panels) conditions

\section{MODEL SOLVER}

The simulations carried out in this study were performed using the MIKE 21/3 Flexible Mesh System developed by the Danish Hydraulics Institute in Denmark (www.dhigroup.com). The solvers for flow, waves and sediment transport are coupled online to compute the morphodynamics. Finite volume method is used to solve the differential equations. The spatial distribution consists of flexible meshes of 
triangular elements. Water levels and current velocities are obtained from the solution of the continuity and momentum equations. The energy conservation equation is used to compute the wave spectrum. Wind-wave generation, wave-wave interaction, wave breaking, bottom-friction, and whitecapping are the sinks and sources for the computation of the wave energy. The computation of wave properties takes into account changes in water levels and current velocities. Radiation stresses are used to compute wave-induced currents. The transport of bed load and suspended sediment load is computed applying the empirical equations of Engelund and Fredsøe (1976). The bed load formulation is based on the probability of the sediment grain to start moving, in which the critical Shields parameter is considered a criterion within the equation. In the transport of suspended sediment, the reference concentration near the bed is calculated based on the empirical formulation proposed by Zyserman and Fredsøe (1994). The bed elevation changes are obtained by solving the sediment continuity equation.

\section{REGIONAL AND LOCAL MODELS}

Regional and local models have been developed and applied to simulate the hydrodynamics and morphodynamics in the study area. On the regional scale a two-dimensional depth-averaged (2D) hydrodynamic model covering the entire Baltic Sea (BSRmod) was set-up. The mesh of the model is composed of about 5100 elements with a grid resolution close to the study area of $1 \mathrm{~km}$ approximately. The model is driven along the open sea boundary with the North Sea using measured water levels from the Kungsvik station as indicated in Figure 4. The wind forcing data stem from the results of meteorological models developed by the German Weather Service (DWD). Model calibration and validation were carried out against measured water levels and wave-climate at several locations. The quality of the simulations performed by BSRmod proved to be adequate to provide reliable hydrodynamic information close to the open boundary of the domain of LBLmod. Relative mean absolute errors (RMAE) were compared with the reference values recommended by Van Rijn et al. (2003). With respect to the recommended values, the model fulfills the criteria for good quality regarding the simulation results (see Jimenez et al., 2009).

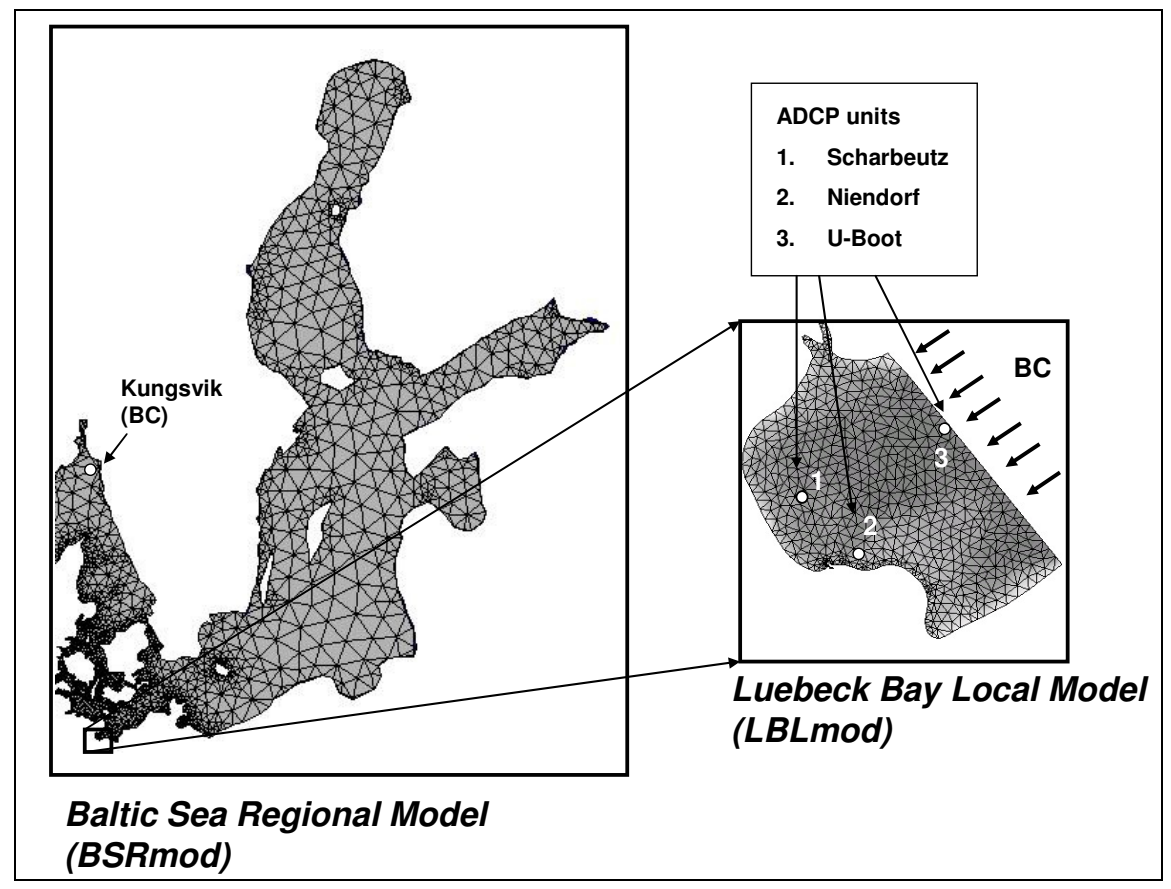

Figure 4. Nesting sequence and gauge stations in the study area

On the local scale, a 2D morphodynamic model covering the entire Luebeck Bay (LBLmod) was developed. The model grid comprises of about 9050 elements with grid resolutions varying from $100 \mathrm{~m}$ to $250 \mathrm{~m}$. The LBLmod is nested within the BSRmod. Water levels and waves from the BSRmod are imposed along the open sea boundaries of the LBLmod. The model has been calibrated and validated 
using measurements of water levels and waves at several locations in the inner Luebeck Bay (see location of ADCP units in Figure 4). The field data and, numerical results of water levels and waves are presented in Figure 5a and Figure 5b, respectively. Simulations covered a one week period from 1 to 7 of January 2008. A sufficient warming up period was applied. The models are driven by measured water levels at the open sea boundary with the North Sea and by wind fields over the entire Baltic Sea. In this study wind fields from the COSMO- EU meteorological model of the DWD were used. It can be seen that the flow and wave models are able to predict water levels and the wave heights reasonably well (see Figure 5a and Figure 5b). The time step for both local and regional models is 10min. The sediment transport rates and the bed levels are computed at every time step and the flow fields are updated.

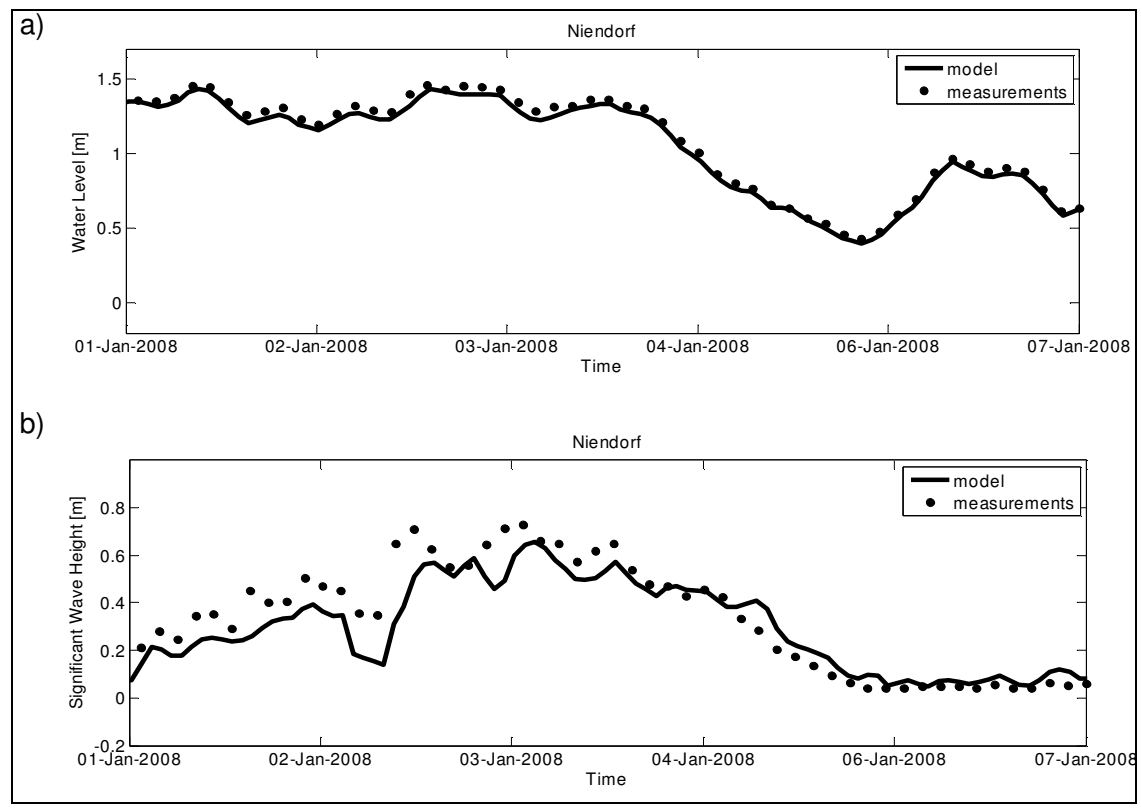

Figure 5. Comparisons of measured and modeled water levels (a) and significant wave heights (b) at the Station Niendorf -1 to 7 of January 2008

\section{PROPOSED METHODOLOGY}

To account for the effect of storms on the medium-term, a methodology consisting of the following steps is proposed: 1) estimation of the representative bathymetrical changes due to storms, 2) selection of a representative period of normal conditions for simulation on the medium term and 3) ensemble of the effect of storms (step 1) with the representative period of normal conditions (step 2). More detailed description of the three steps is given in the following sections.

\section{Step 1: Short term bathymetrical changes due to storms}

The most relevant bathymetrical changes produced as a result of storm events are obtained by means of the so-called empirical orthogonal functions (EOF). EOF is a data-filtering technique that can be used to determine the most relevant temporal and/or spatial patterns of a given variable (Preisendorfer, 1988). EOF is used to appreciate the distribution of the most representative bathymetrical changes produced by typical storms in the area.

In this study the most representative features of the bathymetrical changes of the extreme events were analyzed on the basis of simulations of 16 synthetic storms. Details about the synthetic storms and results of the hydrodynamic simulations are summarized in Schmitz (2007), Bruss et al. (2009) and Jimenez et al. (2009). Figure 6 sketches the approach adopted. Initially a set of synthetic scenarios of extreme events are simulated. As an example, Figure 7 shows the resulting bathymetrical changes produced by four out of the sixteen storm scenarios. The differences in the distribution of the morphological changes may indicate particular patterns of sediment transport depending on the hydrodynamic conditions of each scenario. Subsequently, the resulting bathymetrical changes are organized in a matrix in which the rows represent the maps of bathymetrical changes due to simulated storms, and the columns consist of the position of each element of the computational mesh within the 
domain. The eigenvectors, principal components and eigenvalues are then calculated using the matrix mentioned above. In Figure 8 the percentage of representation of the various modes of the EOF for the conditions in question is shown. It can be seen that the first and second modes account for about $84 \%$ of the information. Moreover, the modes higher than 2 account for only up to $3.6 \%$ of the bathymetrical changes. Finally, the modeled morphological changes due to the various storms are compiled leading to the most representative morphological changes due to one storm in the area.

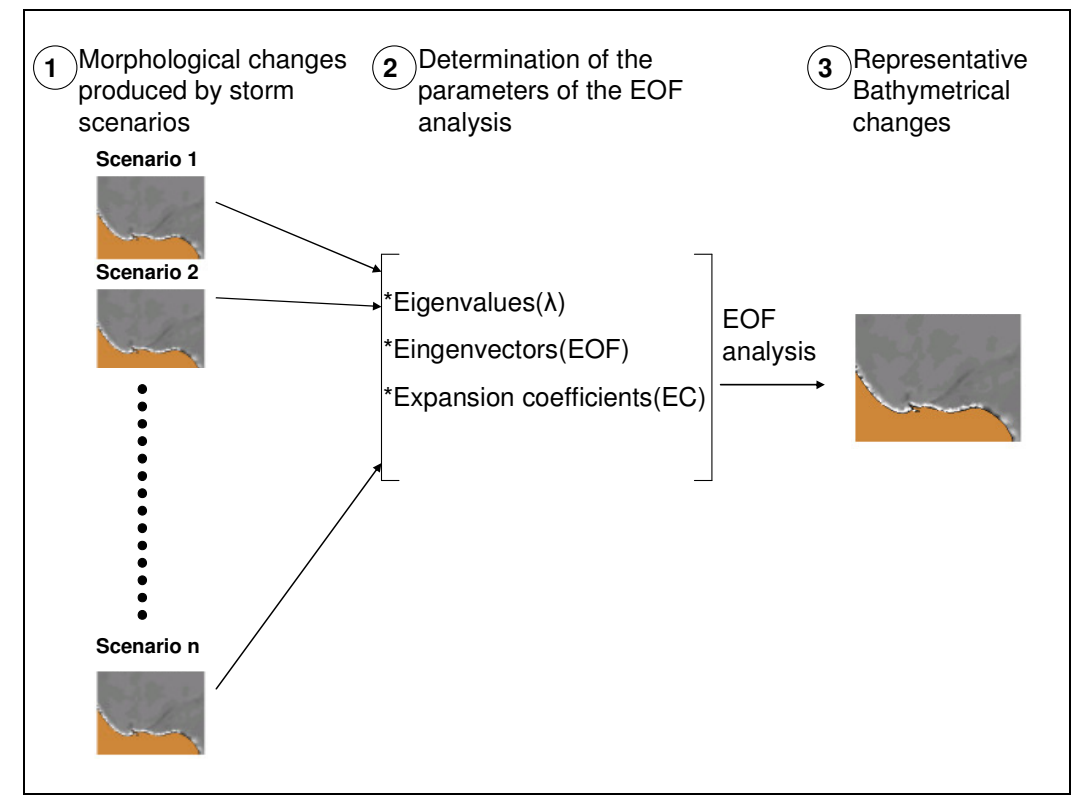

Figure 6. EOF analysis for estimation of the most representative morphological changes due to storms

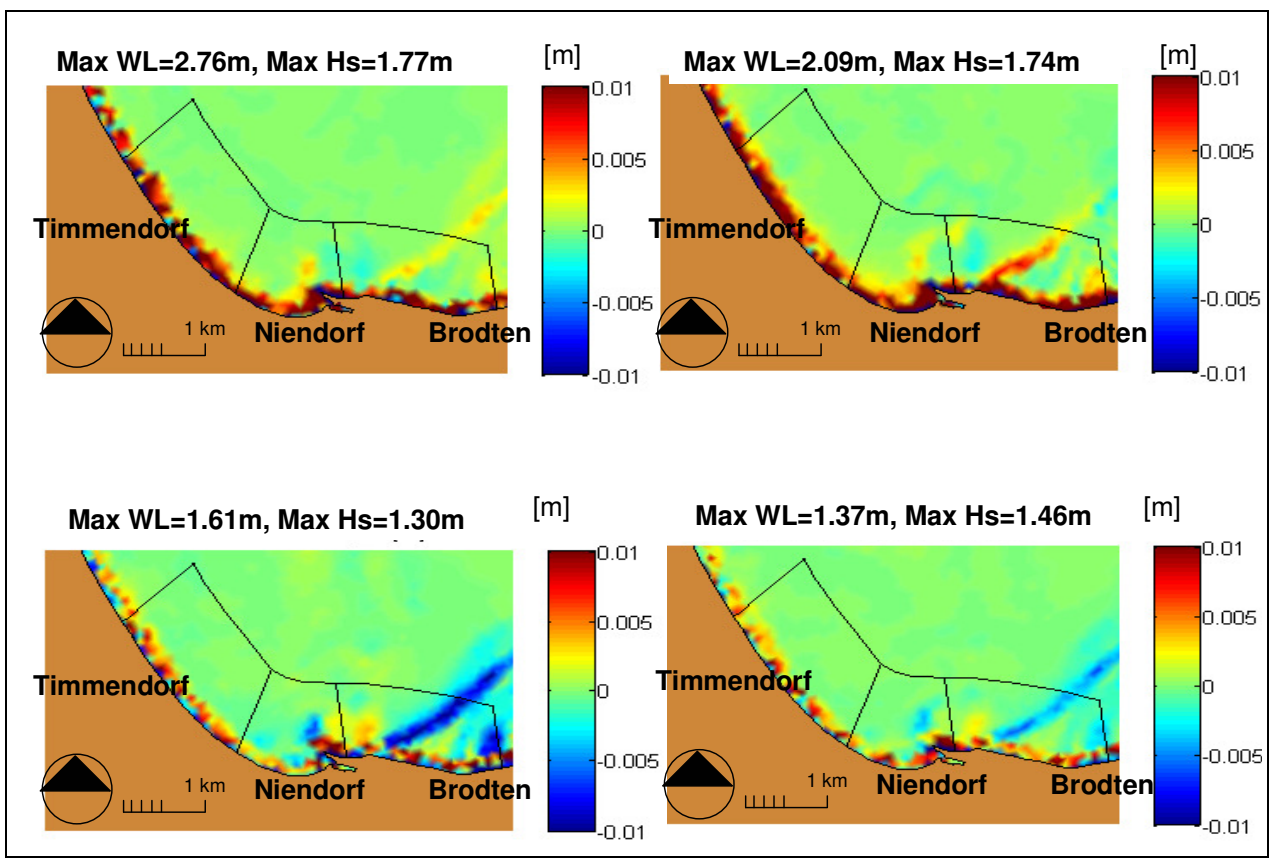

Figure 7. Morphological changes produced by four synthetic storms with distinct intensities 


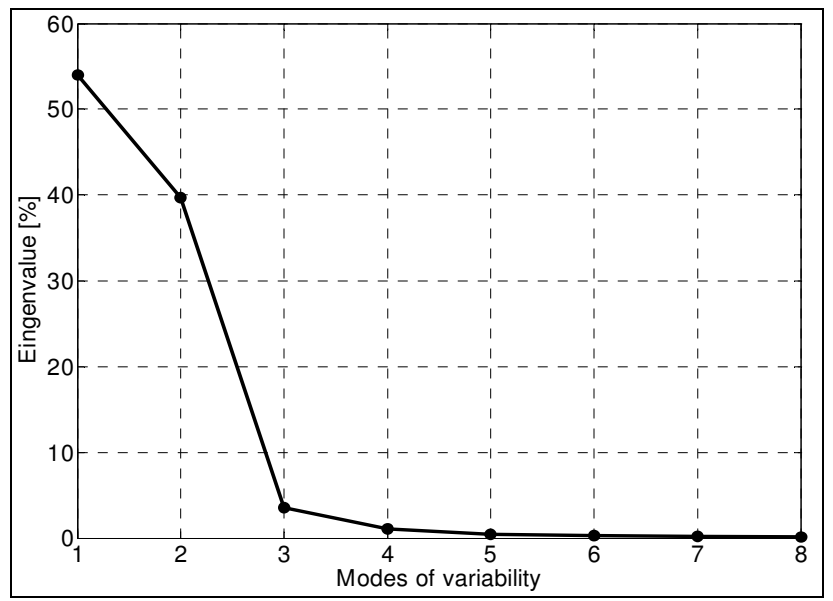

Figure 8. Eigenvalues from the total set of bathymetrical changes produced by the storms

To account for the effect of all the storms in the area during the period in question the total number of storms needs to be estimated in this period. This is done by analyzing the water level variation over the medium-term period. In this study the criterion for storm is linked to the change in measured water levels exceeding $1 \mathrm{~m}$. The maximum values of water levels from the synthetic scenarios were in the range between $1.0 \mathrm{~m}$ and 2.5m; whereas, measured water levels from 1997 until 2007 showed increases in water levels of up to about $1.8 \mathrm{~m}$. Subsequently, 23 storms were identified during the period in question as presented in Figure 9.

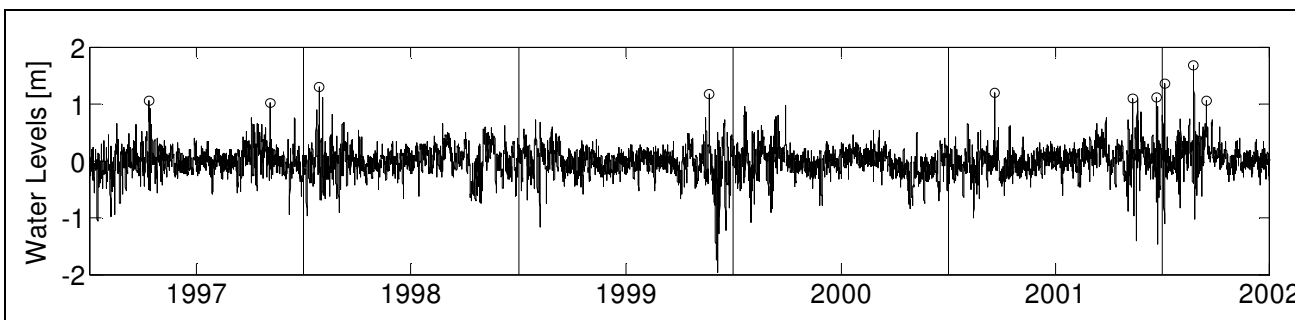

a) First Half of the period (from 1997 until June 2002)

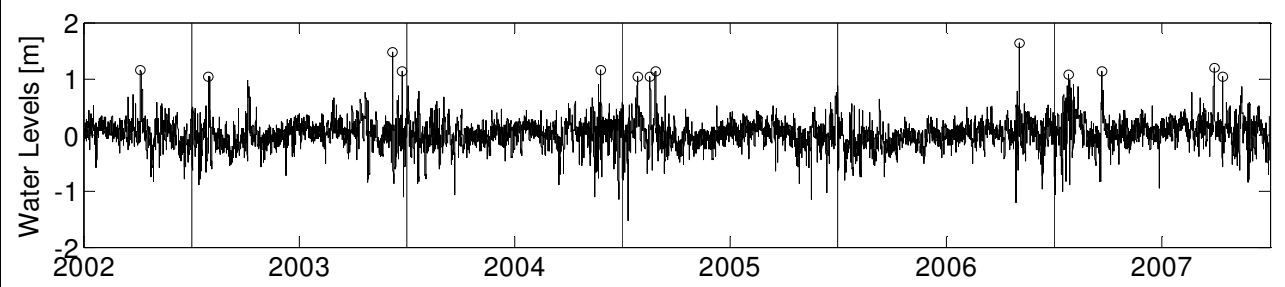

b) Second Half of the period (from July 2002 until 2007)

Figure 9. Identification of the number of storms from 1997 till 2007

\section{Step 2: Medium term morphodynamics}

Due to the fact that the morphodynamic model simulations are computationally time-consuming, predictions on the medium and long term must be accelerated for practical use. Roelvink (2006) proposed a morphological acceleration factor in conjunction with a representative period. The morphological acceleration factor (morfac) is a device used to assist in dealing with the difference in time-scales between hydrodynamic and morphological developments. It works very simply by multiplying the changes in bed elevation due to sediment transport by a constant factor, thereby 
effectively extending the morphological time step. Thus the long-term morphological simulations can be achieved using hydrodynamic simulations of only a fraction of the required duration. In this study the selection of the representative period of normal conditions follows the approach based on the costfunctions method proposed by Boon (2002):

$$
\begin{aligned}
& C 1=\left(W n-W n_{-} l t\right)^{2}+\left(W e-W e_{-} l t\right)^{2} \\
& C 2=\left(\sigma_{W n}-\sigma_{W n_{-} l t}\right)^{2}+\left(\sigma_{W e}-\sigma_{W e_{-} l t}\right)^{2} \\
& C 3=\frac{C 1}{\sigma_{C 1}}+\frac{C 2}{\sigma_{C 2}}
\end{aligned}
$$

where, in $\mathrm{C} 1, \mathrm{Wn}$ and $\mathrm{We}$ are the averaged values of water levels and wind speeds that are computed based on the data of a selected short period. Wn_lt and We_lt are respectively the mean values of water levels and wind speeds computed for the longer period. In C2, $\sigma_{\mathrm{Wn}}$ and $\sigma_{\mathrm{We}}$ are the standard deviations of water levels and wind speeds for the short period, respectively; while, $\sigma_{\mathrm{Wn} \_l t}$ and $\sigma_{\mathrm{We} \_l t}$ are the standard deviations of water levels and wind speeds for the longer period, respectively. In $\mathrm{C} 3$, both $\mathrm{C} 1$ and $\mathrm{C} 2$ functions are normalized by their standard deviations $\left(\sigma_{\mathrm{c} 1}\right.$ and $\sigma_{\mathrm{c} 1}$, respectively). A minimum value in all the three aforementioned functions helps to identify the period of representative conditions.

The wind velocities and water levels in 2007 constituted the most complete set of data available from 1997 till 2007. It is also to consider that the yearly mean absolute value of the surface elevation for the period in question closely resembles that of the year 2007 (i.e., $0.17 \mathrm{~m}$ and $0.19 \mathrm{~m}$, respectively). Thus, the hydrodynamic conditions are assumed as representative on the medium-term. Figure 10 shows the resulting value of cost functions. Note that the three cost functions have a minimum value during the one-month period between November 21 and December 21. Considering a one-month representative period, a morfac equal to 120 would be required for predictions of medium term morphodynamics from 1997 till 2007. It is interesting to notice that the selected period covers averaged weather conditions typical of the study area. Outliers such as storms and more relevant variations with respect to the mean are not present. This can be seen by a comparison of the cost function $\mathrm{C} 3$ for the selected period with the measured water level variation in the same period (see Figure 11). Notice that during the period in question the increases in water level do not exceed $0.5 \mathrm{~m}$ being well below the $1 \mathrm{~m}$ threshold assumed in the selection of the storms.

\section{Step 3: Medium term morphodynamics including the effects of storms}

In this step the morphological changes on the medium-term are obtained by adding the contributions due to storms and for normal weather conditions. It should be emphasized that the procedure is an extreme simplification of the reality. As a first approximation it should be considered that the superposition of bathymetrical changes accounts for the effect of initial bathymetries and the variation in the intensities of the storms is disregarded. In the proposed methodology the map of representative bathymetrical changes obtained in step 1 is multiplied by the total number of storms. The resulting morphological changes are added to the reference bathymetry. The medium term morphodynamics are obtained from numerical model simulations using the morphological acceleration factor equal to 120 in conjunction with the representative period shown in Figure 11. Finally, both contributions, i.e. the ones due to the storms representative bathymetrical changes and representative period of normal conditions, are brought together. The preliminary results that are obtained in this investigation are then analyzed. 


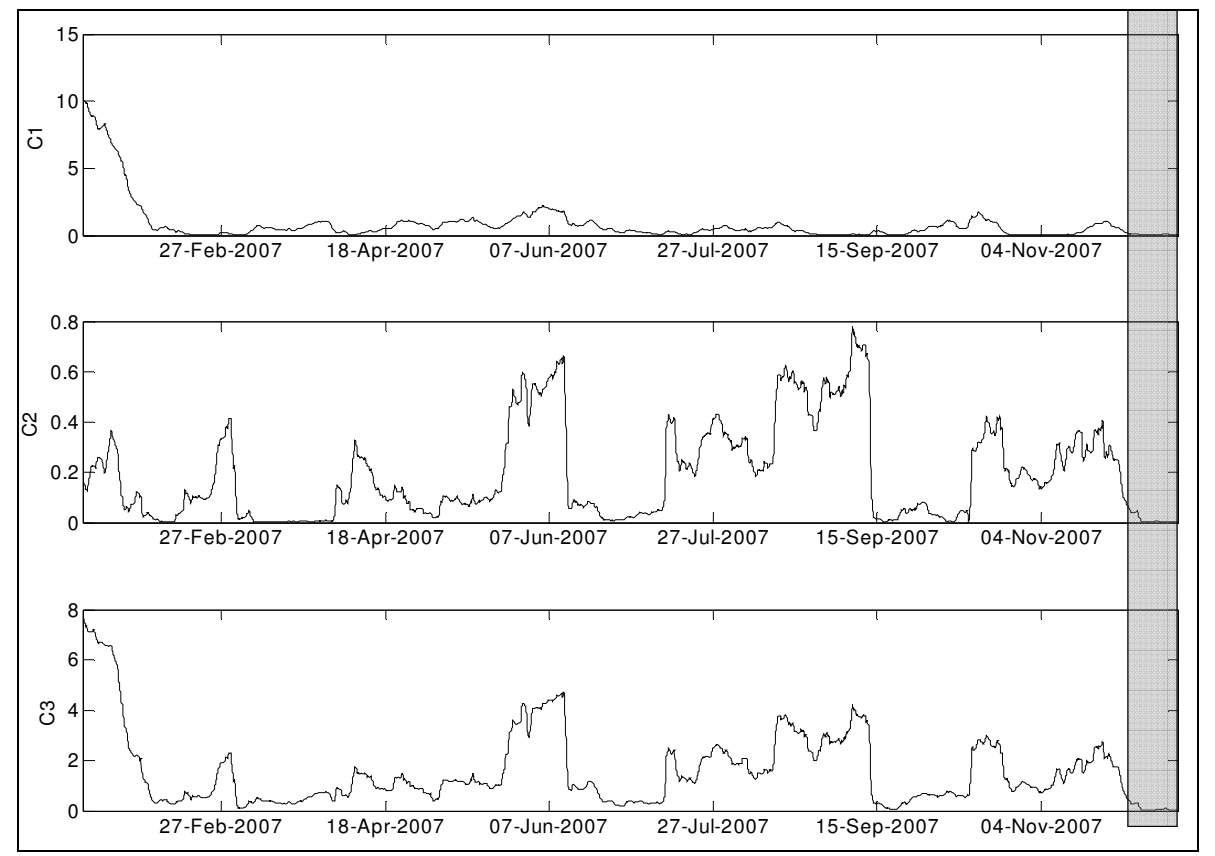

Figure 10. Cost functions for the period January to December 2007 (stripe shows the selected period)

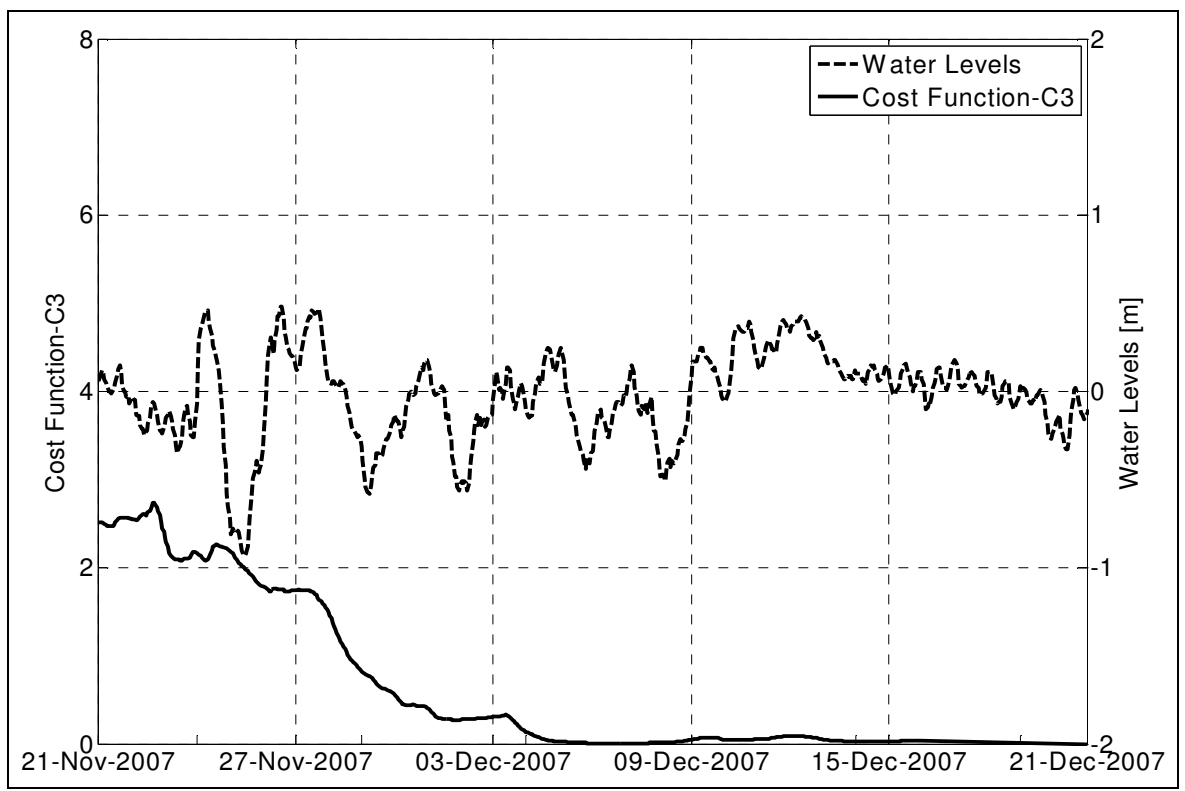

Figure 11. Cost Function $\mathrm{C} 3$ and water levels during the representative period of normal conditions

\section{SENSITIVITY TO THE EOF-MODES}

Sensitivity studies with respect to the EOF-modes were carried out. For that purpose comparisons of simulated and measured volumetric changes of the bathymetry in the study area are carried out for the period 1997 till 2007. To facilitate the analysis the coastal zone along the inner Luebeck Bay was split into three shore areas as shown in Figure 2. It includes Area 1- Timmendorf of area of about $3.4 \mathrm{~km} 2$; Area 2- Niendorf of about $2 \mathrm{~km} 2$ and Area 3- Bodten of about 2.8km2. Simulations considering one, two, five, ten and sixteen EOF-modes were carried out. Comparisons of the measured and computed volumetric changes in the selected areas are shown in Figure 12. In general, the model results show different tendencies of deposition and/or erosion in the defined areas. In Area 1 all cases, except the ones considering mode ten and sixteen, show a tendency of more deposition of sediment with 
increasing number of modes. As for Areas 2 and 3, no clear tendency in the volumetric changes can be identified based on the number of modes. Note that the first two modes were the only cases in which the numerical results were consistent with the deposition/erosion tendency shown in the measurements for all of the three areas. The foregoing agrees with the analysis presented in Figure 8, thus, it is demonstrated that the first two modes represent $84 \%$ of the information contained in the bathymetrical changes produced by the storms. Figure 13 shows the computed representative bathymetrical changes produced by storms corresponding to mode one (right) and mode two (left). Through the EOF analysis, the morphological changes represented by the first two modes consisted of a combination of patterns of sedimentation and erosion along the coast.

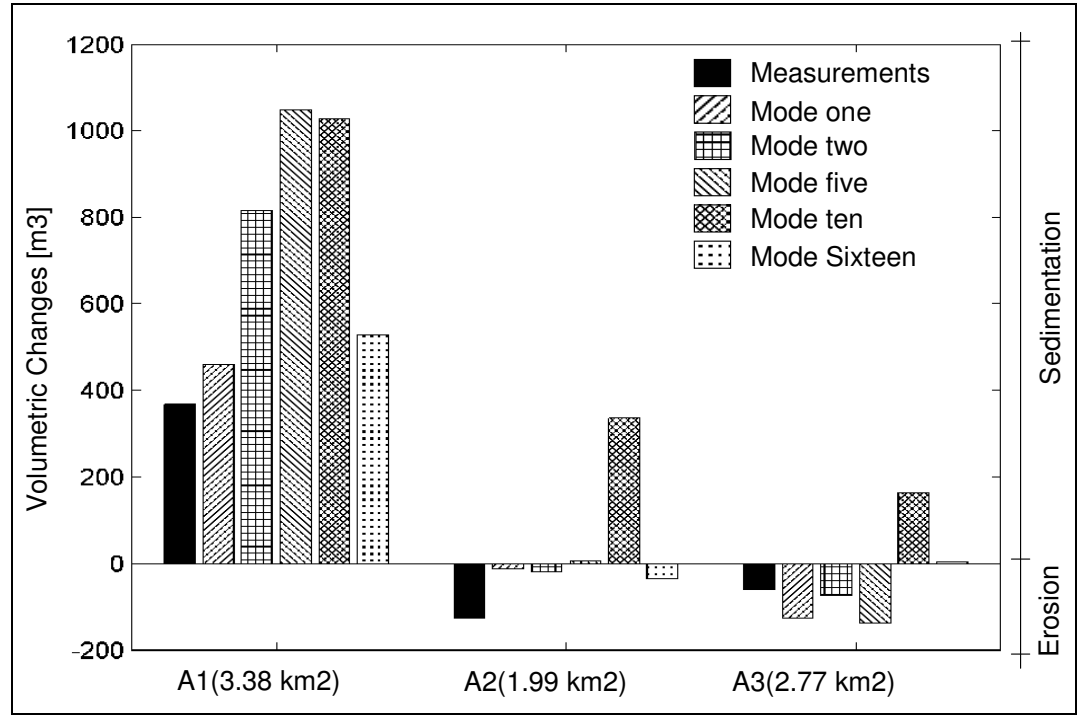

Figure 12. Volumetric changes based on the number of EOF modes

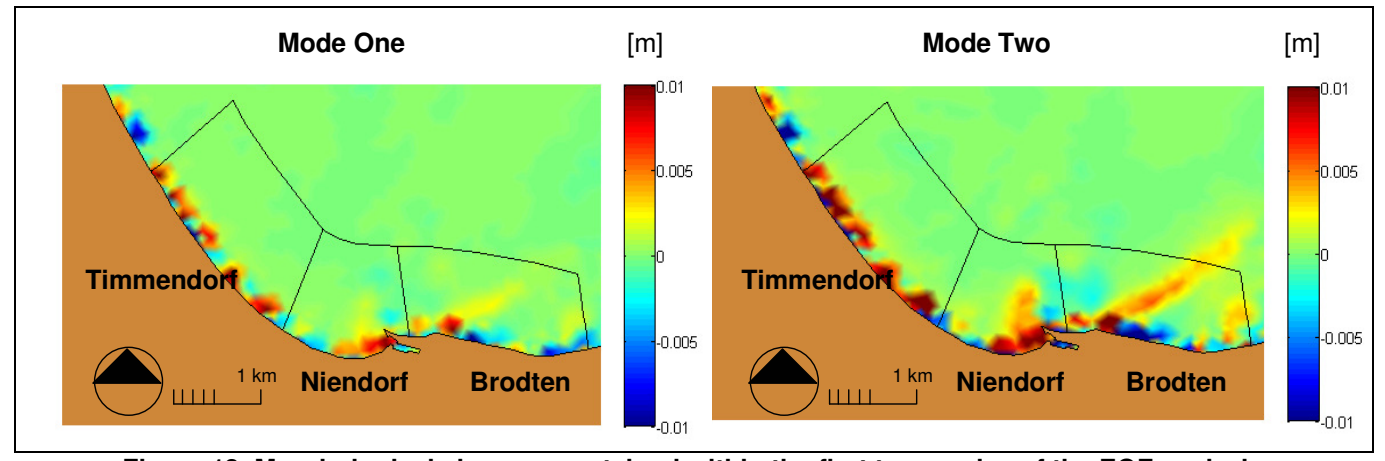

Figure 13. Morphological changes contained within the first two modes of the EOF analysis

\section{SENSITIVITY TO THE OVERLAY OF THE STORMS}

The effect of the sequence of overlay of the effect of storms on the bathymetrical changes was also investigated. Table 1 lists the five cases considered in this study. Cases A and E represent situations in which the effects of the 23 storms were applied respectively before and after the period of the normal conditions. Cases B, C and D represent situations in which the effect of part of the storms were assumed to occur before and some after the period of the normal conditions.

Figure 14 shows the results of the simulations for the different settings as explained above (cf. Table 1). The dependency between the morphological changes and the sequence of the overlay of the storms, stresses its relevance to the performance of the methodology. It can be seen that the increase in the number of storms prior to the simulation of the normal conditions causes a decrease in the sediment deposition in the Area 1 and an increase in the erosion in Area 2. In the eastern Area 3, the tendency of erosion is reduced as the number of storms at the beginning of the simulations was increased from 0 to 12 (i.e., from Case A to Case D, respectively). 'Case E' represents an exception to the tendency in Area 
3, leading to the highest values of erosion in that area. Among all the configurations, the distribution of the storms represented by 'Case C' proved to be close to the measurements observed in the three areas of the analysis. In the following section, i.e. in the preliminary assessment of the methodology, the first mode of the EOF analysis, and the storms sequence overlay in 'Case C', will be used for the medium term morphological simulations.

Table 1. Settings used in the analysis based on the overlay sequence of the storms

\begin{tabular}{|c|c|c|}
\hline \multirow{2}{*}{} & \multicolumn{2}{|c|}{ Overlay sequence of the storms } \\
\cline { 2 - 3 } & $\begin{array}{c}\text { Nr. of storms applied before the } \\
\text { simulation of normal conditions }\end{array}$ & $\begin{array}{c}\text { Nr. of storms applied after the } \\
\text { simulation of normal conditions }\end{array}$ \\
\hline Case A & No Storms & 23 Storms \\
\hline Case B & 6 Storms & 17 Storms \\
\hline Case C & 8 Storms & 15 Storms \\
\hline Case D & 12 Storms & 11 Storms \\
\hline Case E & 23 Storms & No Storms \\
\hline
\end{tabular}

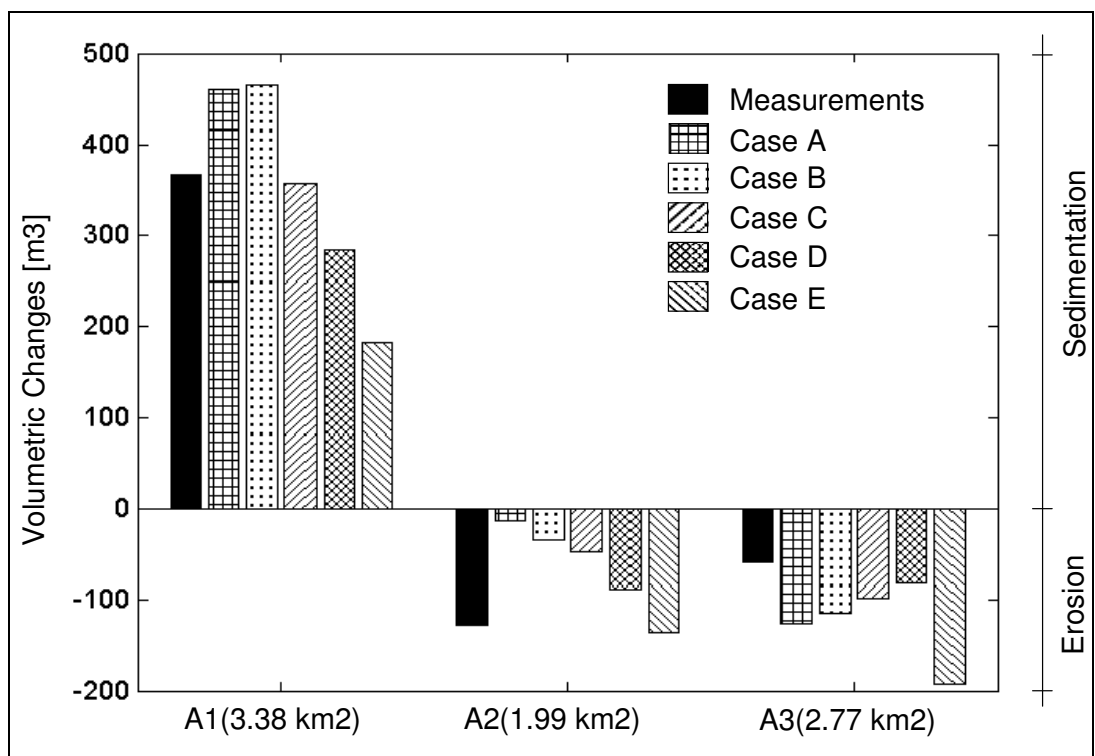

Figure 14. Volumetric changes based on the overlay sequence of the storms

\section{ASSESSMENT OF THE METHODOLOGY}

The effectiveness of the methodology in predicting the volumetric changes in the study area from 1997 till 2007 was assessed by conducting simulations considering: a) only the effects due to the normal conditions, b) the effects of both normal conditions and storms and c) only the effects due to the storms.

Figure 15 shows the resulting volumetric changes in the selected areas in Figure 2. Different morphological processes can be identified in each of those areas. For example, in the coastal zone in front of Timmendorf (see A1 in Figure 15), deposition of sediment in the medium-term scale is expected. The numerical results pertaining to medium term morphodynamics with storms are consistent with the field measurements. In the area A2 (see Figure 15), on the other hand, the simulation results in general are not particularly in agreement with the magnitude of erosion that was measured. The discrepancy may be due dredging activities in Niendorf Harbour that was not accounted for in the simulations. In the third area (see A3 in Figure 15), the model results and measurements agree on the medium-term tendency of erosion in front of the Brodten Cliff-coast. In that section of the coast, even though the erosion was overestimated in both cases, for the cases including and not including the storms, it has been demonstrated that by considering the effects of the storms the model results were closer to the measurements.

Figure 16 shows the spatial distribution of the medium-term morphological changes of the study area. Discrepancies between numerical results and measurements were observed along the shoreline of the Luebeck Bay. The model predicts a higher activity of sedimentation and erosion in the near-shore zone. Such condition is most probably associated with the movement of the bars along the shore-line of 
the bay. Such discrepancies between model results and measurements were not that important for the balance of the volumetric changes in the areas presented in Figure 15. In Figure 16 not much difference between the results of the simulations with and without the effect of storms can be seen. In both cases the differences are barely observed close to the shore-line. The distribution of such differences can be associated with the patterns of bathymetrical changes of the storms alone as shown in the lower-left panel of Figure 16.

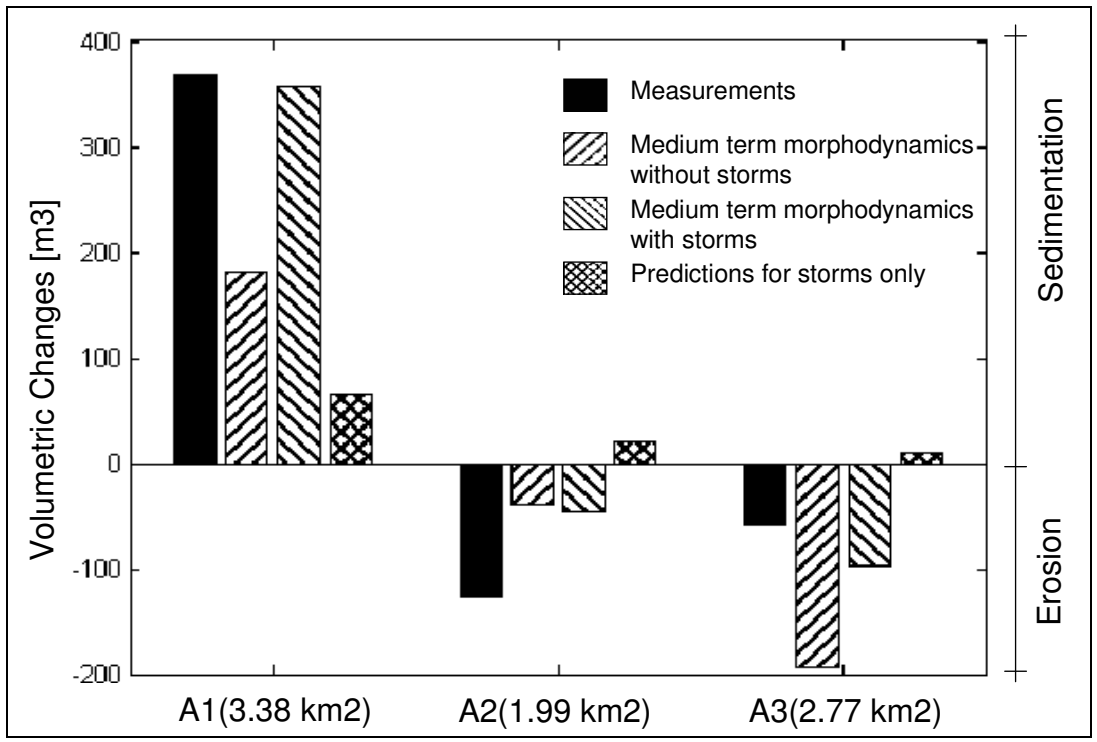

Figure 15. Comparison of measured and predicted volumetric changes

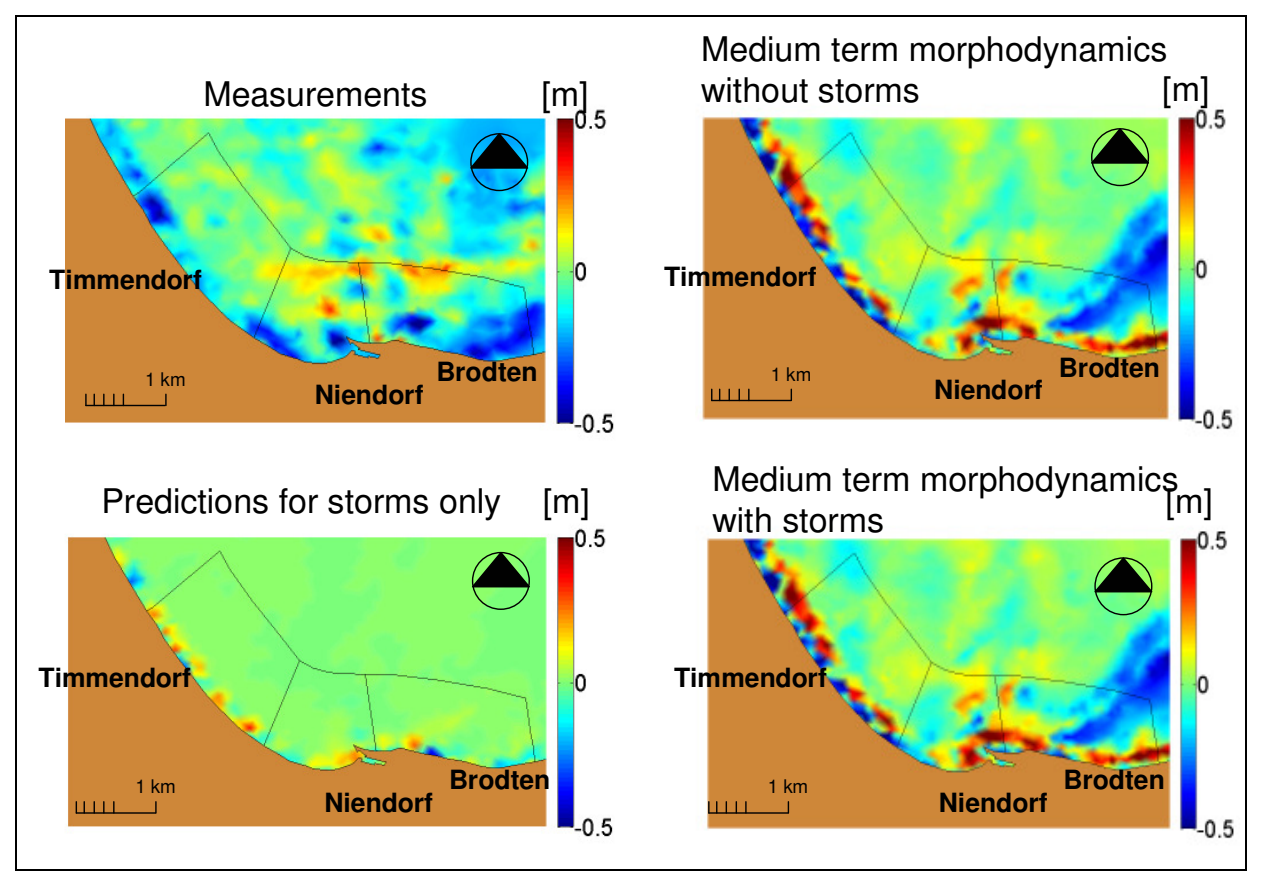

Figure 16. Comparison of measured and modeled morphological changes from 1997 till 2007

\section{CONCLUSIONS}

In this paper preliminary results of a methodology for medium-term morphodynamics accounting for the effects of the storms has been presented. Bearing in mind the simplicity of the methodology in the scheme to integrate the storm effects in the medium-term morphological simulations, the authors analyze the preliminary results of the medium term morphological changes on the Baltic Sea coast. 
During the development of the proposed methodology, 16 synthetic storms have been evaluated based on the empirical orthogonal functions technique. In addition to that, the computational time has been speeded up applying a morfac equal to 120 in conjunction with a representative period which does not include storm periods. Through the analysis of the empirical orthogonal functions, it has been found out that most of the effects on the bathymetry produced by the abovementioned synthetic storms may be well represented by the first two modes from the EOF analysis. In the morphological simulations of medium-term, 23 storms events in a period from 1997 till 2007 were taken into account. A simplified procedure to include the effects of the storms in the medium-term morphodynamics is applied in this investigation consisting of a superposition of representative bathymetrical changes accounting for the 23 storms mentioned above. The sensitivity analysis on the morphological change due to both the number of modes and the overlay sequence of the storms showed the influence of the set-up scheme of the methodology. A preliminary assessment of the methodology based on the volumetric changes demonstrated that the inclusion of the storms produces results in closer agreement with the observations. Regarding the evolution of the bathymetry along the coast of the Luebeck Bay, this study indicated that, in the medium-term period, more sedimentation in the west and more erosion in the central and eastern zone of the Luebeck Bay may be expected. The results showed also that higher sediment activity takes place near the coast. Nevertheless, it has to be born in mind that the proposed methodology could be considered primarily as a tool of quick assessment of the tendencies in the medium- and long-term of the bathymetrical changes. The shortcomings of the method used in the superposition of the storms need to be overcome. Further research is necessary by considering the real chronology and intensity of the storms.

\section{ACKNOWLEDGMENTS}

Measured data of water levels and waves for the calibration and validation of the numerical models were possible thanks to the Federal Waterways and Maritime Administration and the National Bureau for Environment and Nature in Rostock, Germany. The authors wish also to thank the Coastal Sedimentology Unit at Institute of Geosciences for providing an updated bathymetry of the study area. The support of the Research and Technology Centre of the University of Kiel for providing the computational and financial support in this academic work and for helping in the deployment and processing of ADCP measurements is acknowledged.

\section{REFERENCES}

Anderson, T.R., Frazer, L.N., Fletscher, C.H., 2010. Transient and persistent shoreline change from a storm. Geophys. Res. Lett., 37, L08401, doi:10.1029/2009GL042252.

Boon, J., Kerkamp, H., Dardengo, L., 2002. Alternative dumping sites in the Ems-dollar estuary.

Bruss, G., Jimenez, N., Mayerle, R., 2009. Bestimmung von Bemessungsparametern für Küstenschutzanlagen and der Deutschen Ostseeküste aufbauend auf Szenariosimulationen. Die Küste, Heft 75 (in German).

Costas, S., Alejo, I., Vila-Concejo, A., Nombela, M.A., 2005. Persistence of storm-induced morphology on a model low-energy beach: A case study from NW-Iberian Peninsula. Mar. Geol. 224, 43-56.

Dietrich, G. and Weidemann, H., 1952. Stromverhältnisse in der Lübecker Bucht, Die Küste 1 (in German).

Engelund, F. and Fredsøe, J., 1976. A sediment transport model for straight alluvial channels, Nordic Hydrology, 7, 296-306.

Frazer, L.N., Anderson, T.R., Fletcher, C.H., 2009. Correction to 'Modeling improves estimates of shoreline change', Geophys. Res. Lett., 37, L20401, doi:10.1029/2009GL041993.

Houser, C., Hamilton, S., Meyer-Arendt, K., Oravetz, J., 2007. EOF analysis of barrier island morphological change during Hurricane Ivan. Coastal Sediments, 2007.

Jimenez, N., Bruss, G., Eiben, H., Mayerle, R., 2009. Seegangsmodellierung der Ostsee für Extremereignisse und Rekonstruktion des Sturmes von 1872, die Küste, 75, 191-205 (in German).

Kannenberg, E.G., 1952. Das Lübecker Lokal-Schrifttum über das Brodtener Ufers. Die Küste 1(2), 1214 (in German).

Pratje, 1948. Die Bodenbedeckung der südlichen und mittleren Ostsee und ihre Bedeutung für die Ausdeutung fossiler Sedimente. Dt. Hydrogr. Z., 1, 45-61 (in German).

Preisendorfer, R.W., 1988. Principal component analysis in meteorology and oceanography, Elsevier.

Roelvink, J.A., 2006. Coastal morphodynamic evolution techniques, Coastal Engineering, 53, 277-287. 
Schmitz, R., 2007. Vorhersage von historisch aufgetretenen Stürmen über der Ostsee mithilfe des Ensemble Prediction System und COSMOS (in German).

Schwarzer, K. and Krause, R., 2008. Untersuchung zur Moprh- und Sedimentdynamik im Hinblick auf eine Küstensicherungs- und Hochwasserschutzmaßnahme im Bereich Timmendorf Strand, University of Kiel (in German).

Van Rijn, L.C., Walstra, D.J.R., Grasmeijer, B., Sutherland, J., Pan, S., Sierra, J.P., 2003. The predictibility of cross-shore bed evolution of sandy beaches at the time scale of storms and seasons using process-based profile models, Coast. Eng., 47, 295-327.

Zhang, K., Douglas, B. C., and Leatherman, S. P., 2002. Do Storms Cause Long-Term Beach Erosion along the U.S. East Barrier Coast? J. Geology 110, 493-502.

Zyserman, J.A. and Fredsøe, J., 1994. Data analysis of bed concentration of suspended sediment, Journal of Hydraulic Engineering, ASCE, Vol. 120, No. 9, 1021-1042. 